\title{
Borneo Ultimate Frisbee Team: Agility and Speed in Relation with Playing Position
}

\author{
Datu Md Muallim Datu Moksan ${ }^{1}$, Nur Khairunisa Abu Talip ${ }^{2 *}$, and Kristen $\mathrm{Chou}^{3}$ \\ ${ }^{1,2}$ Faculty of Sports Science and Recreation, Universiti Teknologi MARA, Malaysia \\ ${ }^{3}$ United States of America, NJ 08053 \\ *Corresponding author \\ nurkhairunisa.at@gmail.com
}

\begin{abstract}
The purpose of the study was to investigate a arising Borneo Frisbee team named Ultras on agility and speed performance in relation to the playing position of Ultimate Frisbee players. Sixteen $(N=16)$ athletes ( 8 handlers and 8 cutters) participated in the present study, and the age ranged between 19 to 24 years old. Each athlete was tested with the 505 agility test and 30-meter sprint test to measure agility and speed. The level of significance was set at $.05(p<.05)$. The obtained data was analysed using SPSS 22.0. Independent Sample T-Test was employed to compare the differences in agility and speed between handlers and cutters. Results showed that there is no significance difference in agility between handlers and cutters (playing position) $(p=.192)$ and no significant difference in speed between handlers and cutters (playing positions) $(p=.522)$. The mean of the results showed that handlers were approximately $14.16 \%$ more agile than cutters, while cutters were approximately $49.37 \%$ faster in horizontal speed than handlers.
\end{abstract}

Keywords: Ultimate Frisbee, agility, speed, playing position, handlers, cutters.

Copyright: This is an open access article distributed under the terms of the CC-BY-NC-SA (Creative Commons AttributionNonCommercial-ShareAlike 4.0 International License) which permits unrestricted use, distribution in any medium, for noncommercial purposes, provided the original work of the author(s) is properly cited.

\section{INTRODUCTION}

Ultimate Frisbee, which is also known as Ultimate, is a fast paced, non-contact, mixed team sport played with a flying disc (or frisbee) (National Governing Body for Sport Ultimate in United Kingdom and North Ireland, 2008). According to United States of America Ultimate (2015), Ultimate Frisbee was formed in 1968 by a group of students at Columbia High School in Maplewood, New Jersey. At the 2001 World Games in Japan, Ultimate Frisbee officially debuted as a medal sport (Reynolds \& Halsmer, 2006). Leonardo (2014) claimed that, in the United States alone, 47,000 players join USA Ultimate annually while another 37,000 players sign up for Ultimate Canada in order to join the USA Ultimate series. The first game of Ultimate on Malaysian soil was held in 2000 by a group of expatriate teachers from the International School of Kuala Lumpur (Malaysian Flying Disc Association, 2019). Rodrigo (2017) claimed that Malaysia has become a well-known venue for international competitions with its staging of the Malaysian 
Ultimate Open in 2016. Approximately 800 competitors across 32 teams participated in the annual competition.

The present study recruited one of Sarawak's Frisbee teams, the Universiti Teknologi MARA (UiTM) Ultimate Frisbee team, to measure physical performance components. UiTM Ultimate Frisbee (Ultras) is one of the rising teams in Borneo and has won numerous competitions all across Malaysia and Borneo island. The team's records include winning gold at Karnival Sukan Mahasiswa UiTM (KARiSMA) (2017, 2018, and 2019), silver in Bandar Ultimate Open (2015 and 2016) and Sarawak Ultimate Open (2016) and bronze for Bandar Ultimate Open (2017 and 2018) and Borneo Single Gender Ultimate Open (2017).

Figure 1 shows a summary of the Ultras team's achievements. According to the graph, there was unfortunately a slight decrease in performance in the previous year. Thus, by conducting this research, it could help the coaches and the athletes themselves understand the team, identify problems, and hopefully enhance team performance.

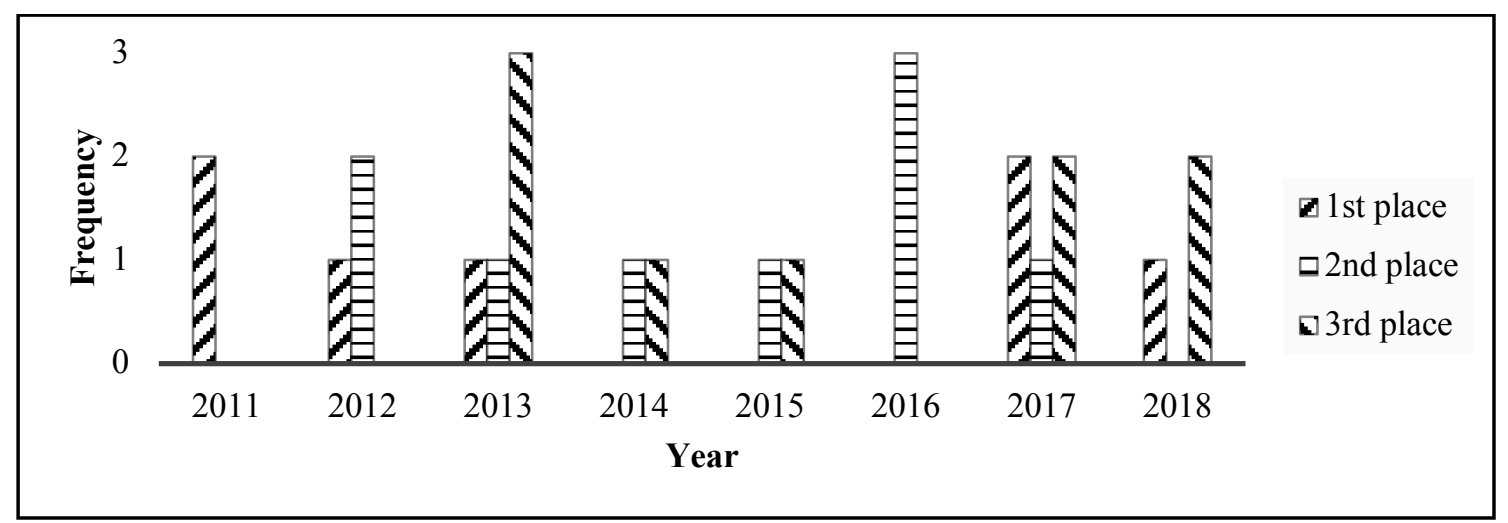

Figure 1. UiTM Ultimate Frisbee's Achievement

Studies on Ultimate are very limited, and, to the extent of the researchers' knowledge, there have not been any studies conducted on Borneo Ultimate Frisbee teams until the current date, though there has been a very limited amount of comparative studies done on the physical components and playing position among Ultimate players. Thus, there is a need to conduct this study to better understand the differences of speed and agility between playing position to provide new findings and knowledge for athletes and coaches.

Ultimate is played by two teams at a time with a flying disc that advances through the air on a field with end zones. Players are not allowed to run with the disc. The objective of the game is to score by catching a pass in the opponent's end zone (Reynolds \& Halsmer, 2006). Ultimate combines elements of football, basketball and rugby, demanding players to run, cut, jump, throw, guard, catch and, at times, layout (dive horizontally with an outstretched arm) for the disc (Reynolds \& Halsmer, 2006). According to Crocket (2012), elite-level Ultimate is a highly demanding and competitive undertaking with significant personal sacrifices that include training for up to 20 hours a week, spending thousands of dollars travelling to tournaments and studying 'play' books.

Ultimate Frisbee is mainly divided into two positions, which are handlers and cutters. Handlers are generally the better throwers of the team, and they work with the cutters to keep the disc in play and prevent stagnation in movements (USA Ultimate, 2010). Handlers are the players that usually have the disc the most, staying the furthest back and passing to reset the stall count (Stowdashay, 2011). Cutters, on the other hand, are the offensive players that move the disc upfield (Stowdashay, 2011) and thus tend to be more athletic, working on the offence in order to 
progress the disc and score (USA Ultimate, 2010).

In Ultimate, the cutters' task normally depends on the strategies used by the team, such as a horizontal or vertical offence (Stowdashay, 2011). In a horizontal offence, four cutters form a straight line across the playing field and make a run (cut) in and out in order to beat opponent's defensive players, whereas, in vertical offence strategies, a vertical line is made in the centre of the field, and cutters maximize the width of space (field) by using or running to the side of the field to beat the opponent's defenders marking cutters (Stowdashay, 2011). However, these positions are not fixed, as there is a chance that handlers will cut and sprint all the way to get a score at the end zone.

Physical conditioning is the base for any sporting performance (Bompa, 2009). Wood (2008) stated that speed and agility are seen as some of the most important factors for success in Ultimate. According to Hakkinen, Rinne, Vasankari, Santtila, Hakkinen and Kyrolainen (2010), the fitness components of players may vary from each other even if the sports involvement and characteristics of the performers are equivalent. In order to facilitate the development and production of successful athletes, it is essential to identify athletes who inherently possess the desired characteristics.

Due to the fast pace of the game, speed and agility are some of the factors required for success in Ultimate. Both offensive and defensive settings of the game would require the ability to perform quick changes in direction and to react to the movements of opponents. Hence, agility is crucial in Ultimate (Sheppard \& Young, 2006) and further study (Neville, 2007) was suggested to measure agility in Ultimate athletes.

Agility is defined as the ability to change direction rapidly and accurately (Alricsson, 2001). Plisk (2008) stated that the basic definition of agility is too simplistic, because it is now thought to be much more complex involving not only speed, but also balance, coordination and the ability to react to a change in the environment. Agility can be seen in various forms, from simple footwork to move the entire body in the opposite direction while running at maximum acceleration. Players need to be agile on the field for them to guard or escape their mark, and catch the disc. In Ultimate, athletes must be agile enough to escape defenders, and this skill is vital at any level of competition (Akinbola, Logerstedt, Hunter-Giordano \& Snyder-Mackler, 2015). Previous studies have also claimed that agility training is a re-enforcement of motor programming through the neuromuscular conditions and neural adaptation of muscles spindles, Golgi-tendon organs and joint proprioreceptors (Barnes \& Attaway, 1996). An Ultimate player who is agile would be able to change direction repeatedly without losing balance.

Speed is defined as the shortest time required for an object to move along a fixed distance (Harman $\&$ Garhammer, 2008). Speed is one of the most important components because players need to be able to move rapidly from one spot to another. This applies to cutters in particular, as their primary purpose is to supply options down-field for the handlers. Apart from that, having speed allows defensive players to keep up with the opponent's offensive players. The faster the player, the higher the percentage is to win the disc from the opponent. Therefore, it is necessary to include speed training into the training program, especially when the coaches notice that the athletes have difficulty keeping up with the teammates or competitors (Raines, 2015).

Speed and agility may be included in the complete spectrum of the training (Brown \& Ferrigno, 2015). Ultimate Frisbee covers almost all fitness components such as speed, power, agility, balance, reaction time and coordination. The skill-related components may vary between the playing positions.

There are different variables and characteristics which are responsible for excellence in sports. 
These factors may be related to the sport itself, as well as to the playing position. A previous study conducted by Singh and Choudhary (2016) on netball players proposed that playing positions have an impact on quickness and also on agility due to a significant difference in skill needed based on the positioning they play. The findings were supported by Delextrat and Cohen (2009) in a study on female basketball players that measured strength, power, speed and agility; it suggested that specific fitness training must be undertaken according to playing position and that different playing positions influence the requirement of the athlete's skill related components. Thus, the study claimed that playing positions have impact on agility and speed performance. Another study conducted by Gil, Ruiz and Irazusta (2007) also revealed that there was a significant difference between playing positions in football. The study claimed that attackers were faster than defenders and midfielders in the 30-meter sprint test. It was also observed that goalkeepers were slightly slower than their defender, midfielder and attacker counterparts. The results therefore suggest that midfielders and attackers are technically more developed than defenders and goalkeepers in football. It was discovered that there were contrasts in the physical performance level related with playing positions. Reeves, Poh, Brown, Tizzard and Ismail (1999) also found that there were differences in the anthropometric characteristics and body composition associated with playing position.

In contrast, another comparative study that was done by Gaurav, Singh and Singh (2015) on football players investigated physical fitness components associated with playing position. It revealed that midfielders and attackers were almost equal in power, speed and agility. In addition, both had demonstrated preferable power and dexterity over their partners: the goalkeepers and defenders. Thus, the research stated that there were no differences in the physical fitness level associated with playing positions. The relationship between physical performance and playing positons is still inconclusive; hence further study should be done in order to pursue a conclusion.

\section{METHODOLOGY}

A Quasi-Experimental design has been used in the present study. Players were divided into two groups according to their handler or cutter player position in Ultimate Frisbee. This study used nonprobability sampling: a purposive sampling technique.

\section{Sampling}

The population focused on ULTRAS, one of the rising Frisbee teams in Borneo. The players were determined by the coach. The inclusion criteria for sampling for the present study included ages ranging from 19 to 24 years old. The sample for this present study consisted of intermediate level players consisting of male and female athletes from ULTRAS who were actively involved in training and competitions such as KARiSMA Perak and Bandar Ultimate Open in 2018. Selected athletes were required to have had playing or participation experience in any competition for at least one year.

Athletes who had experienced any lower extremity injuries or any other type of health issue such as severe musculoskeletal injuries or spinal injuries within 6 months of the study were also excluded (Talip \& Kadir, 2018).

\section{Procedures}

The athletes that participated in the study were divided according to the athletes' playing positions inside the team which consisted of handlers $(n=8)$ and cutters $(n=8)$. All the participants were informed about the testing procedure of any possible risk of injuries. All the athletes completed and agreed to the consent form and passed Physical Activity and Readiness Questionnaire (PAR-Q) as the qualifying screening test. Ethical approval was obtained from the University's Research Committee. Approval for data collection was also retrieved from UiTM Ultimate's coach. 
Dynamic warm ups were applied prior to each and every testing procedure (agility test and speed test). In order to measure agility of the players, the testing protocol of the 505 agility test was used, while speed was measured by the $30 \mathrm{~m}$ sprint test. The athletes were instructed to restrain from any heavy and extreme physical activity 72 to 92 hours prior to the study (Jones, Ambegaonkar, Nindl, Smith \& Headley, 2012). Rest intervals were set for two minutes between trials (Delextrat \& Cohen, 2009) and ten minutes (Nilsson \& Cardinale, 2015) between the testing procedures. The subjects were not allowed to perform any extreme activities 48 hours before the test to avoid fatigue (Yu, 2014).

\section{Instrumentation}

In the present study, the 505 agility test was used to measure athletes' agility performance, while the $30 \mathrm{~m}$ sprint test was used to measure horizontal speed. The 505 agility test was used to measure agility since its required movements best mimic the movement in Ultimate Frisbee, such as cutting the moving disc inside the game. In the 505 agility test, athletes were required to sprint forward to a line $5 \mathrm{~m}$ ahead and pivot $180^{\circ}$ before returning to the start point (Sheppard \& Young, 2006). The similar protocol of the 505 agility test was used in the previous parallel study by Gabbett and Sheppard (2013). According to Barber, Thomas, Jones, McMahon, and Comfort (2015), the 505 agility test measurement has a high reliability value ( $r=0.95$ to 0.97$)$.

On the other hand, the $30 \mathrm{~m}$ sprint test was used to measure speed. Athletes needed to sprint as fast as possible on a $30 \mathrm{~m}$ straight line while a stopwatch (Casio, Japan) was used to record the time. The similar procedure of the $30 \mathrm{~m}$ sprint test was used in the previous study by Kartal (2016). According to Nigro, Bartolomei and Merni (2016), the 30m sprint test measurement also has a high reliability value ( $r=0.94$ to 0.98$)$.

\section{Statistical Analyses}

Normality of the data was analysed using skewness and kurtosis. The obtained data was presented as mean and standard deviation. Independent Samples T-Test was used in comparing data obtained. Significant value was set at $.05(p<.05)$. Data was analysed using the Statistical Package of Social Science (SPSS) version 22.0 in all statistical evaluation.

\section{RESULTS}

Sixteen $(N=16)$ athletes were involved in the present study, with eight of the players playing as handlers $(n=8)$ and another eight playing as cutters $(n=8)$. Based on skewness and kurtosis, the data of the present study was normal with range between -2 to +2 (George \& Mallery, 2016).

Demographic data showed that the mean and standard deviation for age was $20.43 \pm 1.46$ years old. The mean height was $171.66 \pm 1.47 \mathrm{~cm}$, while mean weight was $65.5 \pm 3.88 \mathrm{~kg}$. Figure 2 shows the mean for the 505 agility test of players according to playing positions reported. The mean for handlers was $2.85 \mathrm{~s} \pm .431$ while for mean for cutters was $3.32 \mathrm{~s} \pm .866$. Results show that handlers have higher agility when compared to cutters. Independent Samples T-Test shows that there was no significant difference between playing positions and agility $(p=.192)$.

Figure 3 shows the mean speed between handlers and cutters measured by the $30 \mathrm{~m}$ sprint test. The mean speed for handlers was $4.74 \mathrm{~s} \pm .385$, while the mean speed was $4.62 \mathrm{~s} \pm .346$ for cutters. Results show that cutters have faster linear speed when compared to handlers. Independent Samples T-Test shows that there was no significant difference between playing positions and horizontal speed $(p=.522)$. 


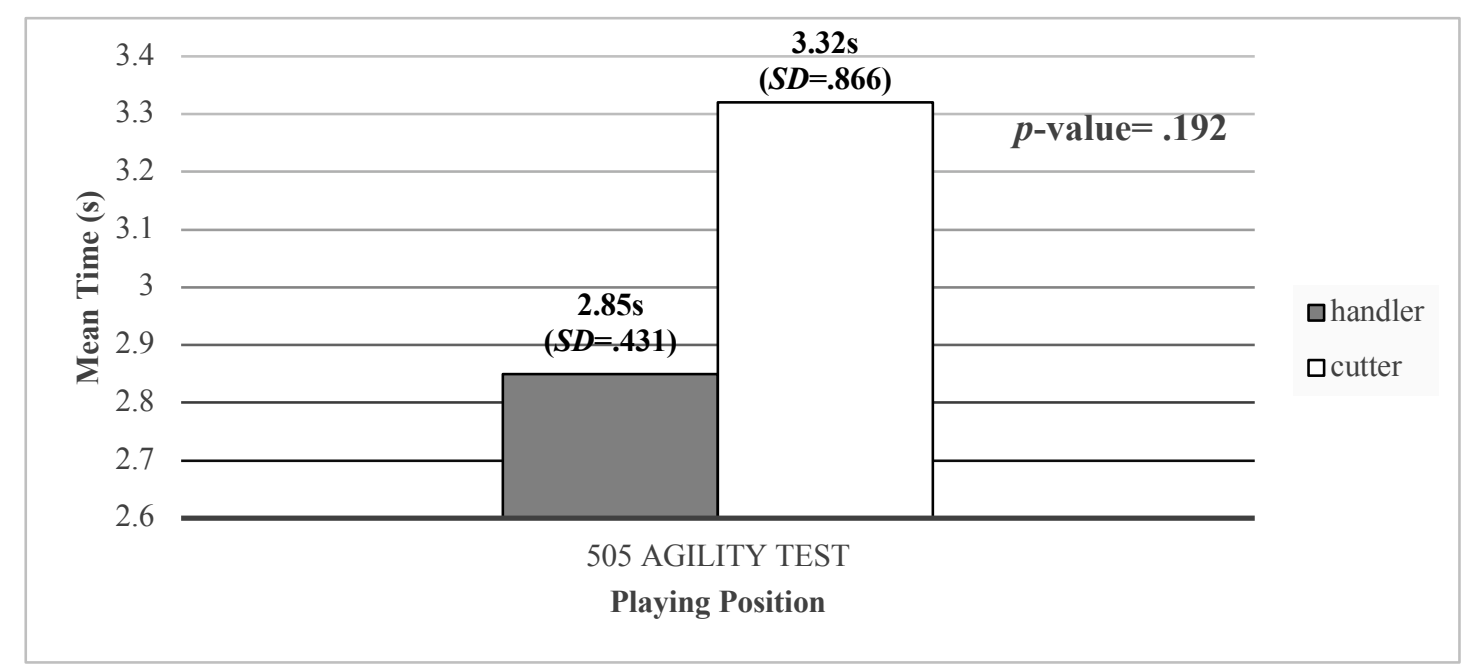

Figure 2. 505 agility test between handlers and cutters

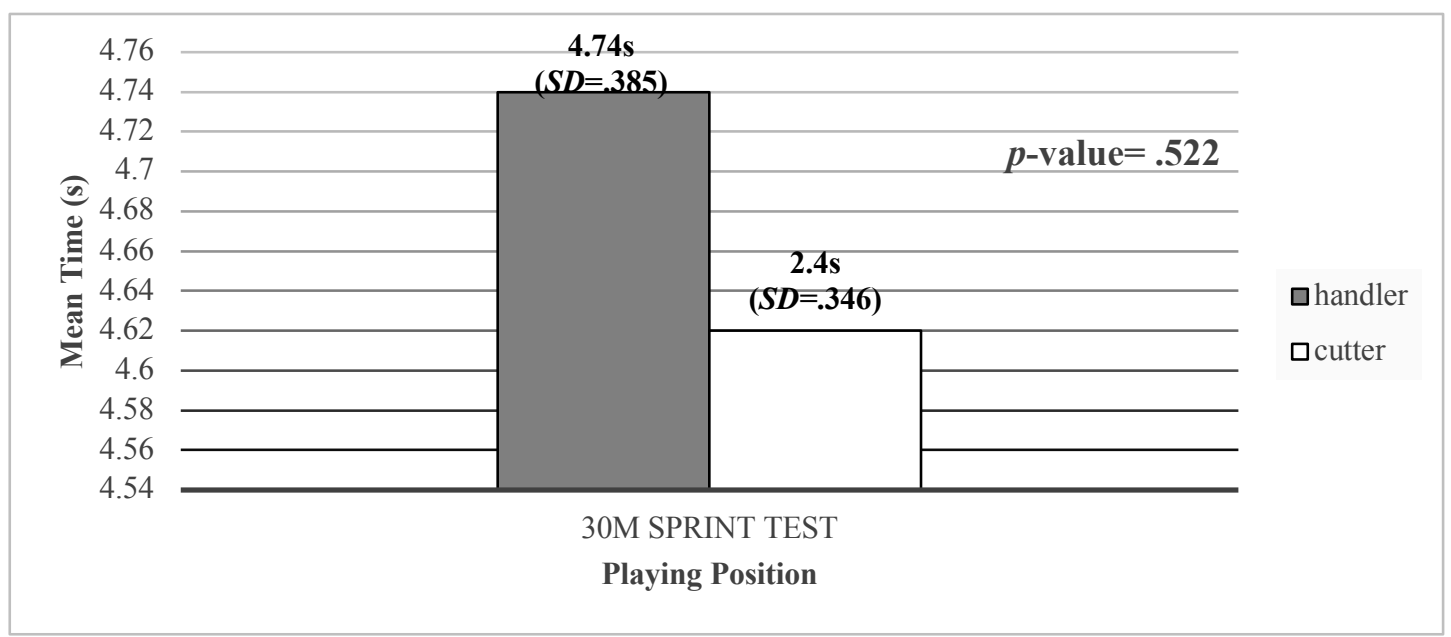

Figure $3.30 \mathrm{~m}$ sprint test between handlers and cutters

\section{DISCUSSION}

There was no significance difference found in terms of agility between handlers and cutters. This was probably due to the demands of the sport which require all the players to perform quick changes in various directions and react to the movements of the opponents in both offensive and defensive strategies depending on the team's tactical plan. During offensive play where the team has the disc and are trying to score, both handlers and cutters need agility to move to empty spaces and pass and receive the disc to attempt a score or point. Defensive play usually requires both handlers and cutters to mark or guard the opponent and, if possible, cut the disc to thwart attempts to score. Hence, the insignificant result is perhaps due to the needs of both positions to have great agility in Ultimate. Sheppard and Young (2006) also claimed that agility is generally crucial in Ultimate.

The $30 \mathrm{~m}$ sprint test showed an insignificant result, suggesting that there were no significant differences found between horizontal speed and playing positions (handlers and cutters). Little and Williams (2005) suggested that in a fast pace game, speed is an attributing factor to success. Therefore, both handlers and cutters need to be able to move rapidly from one point to another to throw or catch the disc, thus explaining the insignificant results in horizontal speed between 
handlers and cutters.

The current study suggested that the physiological demands of Ultimate were the same for either position, as there were no significant differences in either agility or speed in the two playing positions. The present study was parallel to Gaurav et al. (2015), which suggested that positions are flexible to some extent and depend upon whether the team were on offence or defence, thus resulting in the similar physical performance.

The agility and horizontal speed performance between two different positions (handlers and cutters) was similar likely due to the similar training program induced in the athletes. The Specific Adaptation Imposed Demands (SAID) principle claimed that similar result was due to the similar training imposed: agility and speed between handlers and cutters were similar because the identical training programme used. The team trains as a whole (similar training programme) and is not divided according to position in order to encourage team chemistry and understanding. Thus, this factor may contribute to the insignificant results between playing positions. Apart from that, the level of the athletes may also have affected the results thus leading to a deficiency of differences.

Despite the insignificant difference in agility between handlers and cutters, handlers (2.85 seconds) were more agile (in mean) as compared to cutters (3.32 seconds). Thus, handlers were approximately $14.16 \%$ more agile than cutters. This is likely due to the fact that handlers require more sudden changes of direction than the cutters in order to catch the disc, reorganizing the team for another attempt and passing to the cutters to score. The movements and passes could require lots of agility, as opponents may be on defensive strategy and hence marking on every player. This therefore demands the agility of the handlers to find their options as fast as possible.

On the other hand, the cutters ( 2.4 seconds) were shown to have a better horizontal speed (in mean) than the handlers (4.74 seconds). Thus, cutters were approximately $49.37 \%$ faster in horizontal speed than handlers. This is probably due to the demands of the game, which requires cutters to sprint in order to receive the disc from handlers or/and to create a space for the handlers to pass the disc. Therefore, the cutters possessed greater speed in the $30 \mathrm{~m}$ sprint test because sprinting is the main roles for cutters inside the game in order to supply options to the handlers for the disc to move forward and score points. Although the training was similar, the mean of speed test for cutters was faster due to the demands of in-game training itself.

To conclude, there is no significant difference between playing positions (handlers and cutters) in terms of agility or speed. However, the mean showed that handlers were approximately $14.16 \%$ more agile than cutters, while cutters were approximately $49.37 \%$ faster in horizontal speed than handlers.

\section{RECOMMENDATION}

This study has compared the physical performance, notably in terms of speed and agility among Ultimate Frisbee players between two difference positions: handlers and cutters. For future studies, it is recommended to increase the number of athletes that will be used as the test subject and perhaps involve other established team clubs or other sports in the study.

Future researchers also may include other tests of physical performance such as anthropometric measurement, power, reaction time and cardiovascular fitness tests. Apart from that, it would also be fascinating for future studies to include psychological measurement in sports performance as well as psychophysiology on Frisbee athletes. 
Last but not least, it is also recommended for future study to further investigate physical performance and playing position on different sports in Malaysia.

\section{PRACTICAL APPLICATION}

The results of the study can be applied to coaches, sports scientists and even the athletes themselves as reference in order to create a comprehensive training program that does not overlook elements such as playing position and needed physical performance. Considering that the playing position also might also be influenced by athletes' physical performance, the present study would also allow the coach to consider splitting training programs according to the playing position.

The results of this study may help Ultimate Frisbee players acknowledge the key performance factors in Ultimate Frisbee, as well as acknowledge the current physical performance of Borneo Ultimate Frisbee team in order to improve performance in training as well as in an actual game.

\section{REFERENCES}

Akinbola, M., Logerstedt, D., Hunter-Giordano, A. \& Snyder-Mackler, L. (2015). Ultimate Frisbee injuries in a collegiate setting. International journal of sports physical therapy, 10(1), 75.

Alricsson, M., Harms-Ringdahl, K. \& Werner, S. (2001). Reliability of sports related functional tests with emphasis on speed and agility in young athletes. Scandinavian journal of medicine \& science in sports, 11(4), 229-232.

Barber, O. R., Thomas, C., Jones, P. A., McMahon, J. J., \& Comfort, P. (2016). Reliability of the 505 change-of-direction test in netball players. International journal of sports physiology and performance, 11(3), 377-380.

Barnes, M., \& Attaway, J. (1996). Agility and conditioning of the San Francisco 49ers. Strength \& Conditioning Journal, 18(4), 10-16.

Bompa, T. O. \& Haff, G. G. (2009). Periodization: Theory and Methodology of Training. United States of America. Human Kinetics.

Brown, L. \& Ferrigno, V. (Eds.). (2015). Training for Speed, Agility, and Quickness, 3E. Human Kinetics.

Crocket, H. (2012). 'This is men's ultimate': (Re) creating multiple masculinities in elite open Ultimate Frisbee. International Review for the Sociology of Sport, 48(3), 318-333.

Delextrat, A. \& Cohen, D. (2009). Strength, power, speed, and agility of women basketball players according to playing position. The Journal of Strength \& Conditioning Research, 23(7), 1974-1981.

Gabbett, T. J. \& Sheppard, J. M. (2013). Testing and training agility. Australia. Human Kinetics.

Gaurav, V., Singh, A., \& Singh, S. (2015). Comparison of selected physical fitness components among male football players of different playing positions. Turkish Journal of Sport and Exercise; Vol 17, No 2 (2015); 22-25.

Gil, S. M., Gil, J., Ruiz, F., Irazusta, A., \& Irazusta, J. (2007). Physiological and anthropometric characteristics of young soccer players according to their playing position: relevance for the selection process. The Journal of Strength \& Conditioning Research, 21(2), 438-445.

Häkkinen, A., Rinne, M., Vasankari, T., Santtila, M., Häkkinen, K., \& Kyröläinen, H. (2010). Association of physical fitness with health-related quality of life in Finnish young men. Health and quality of life outcomes, 8(1), 15.

Harman, E. \& Garhammer, J. (2008). Administration, Scoring, and Interpretation of Selected Tests. In: Essentials of Strength Training and Conditioning, 3rd ed., Edited by T.R.Beachle, and R.W. Earle, pp.250-292. Champaigh, IL: Human Kinetics.

Jones, M. T., Ambegaonkar, J. P., Nindl, B. C., Smith, J. A., \& Headley, S. A. (2012). Effects of unilateral and bilateral lower-body heavy resistance exercise on muscle activity and testosterone responses. The Journal of Strength \& Conditioning Research, 26(4), 1094-1100 
Kartal, R. (2016). Comparison of Speed, Agility, Anaerobic Strength and Anthropometric Characteristics in Male Football and Futsal Players. Journal of Education and Training Studies, 4(7), 47-53.

Leonardo, P. A. (2014). Ultimate: The Greatest Sport Ever Invented by Man. New York, USA. Breakaway Books.

Malaysian Flying Disc Association (2019). History of MFDA. Retrieved from https://flyingdisc.my/history-of-mfda.

Neville, J. W. (2007). Out of Bounds: College Women's Ultimate Frisbee and the Practice of Gendered Identities (Doctoral dissertation, University of Florida).

Nigro, F., Bartolomei, S. \& Merni, F. (2016). Validity of Different Systems for Time Measurement in 30m-Sprint Test. 8th International Conference for Youth Sport 2016.

Nilsson, J., Cardinale, D. (2015). Aerobic and anaerobic test performance among elite male football players in different team positions. LASE Journal of Sport Science, 6(2), 73-92.

Plisk, S. S. (2008). Chapter 17 speed, agility, and speed-endurance development. Essentials of Strength Training and Conditioning. Baechle TR, Earle RW, eds. Champaign, IL: Human Kinetics, 458-462.

Raines, A. (2015). The Benefits of Speed, Agility and Quickness (SAQ) Drills for Strength and Conditioning Athletes. Retrieved from https://myvega.com/blogs/content/speedagility-drills-for-strength-and-conditioning-athletes

Reeves, S. L., Poh, B. K., Brown, M. Tizzard, N. H. \& Ismail, M. N. (1991). Anthropoetric measurement and body composition of English and Malaysian footballers. Malaysian Journal of Nutrition, 5;79-86.

Reynolds, K. H. \& Halsmer, S. E. (2006). Injuries from Ultimate Frisbee. Wisconsin Medical Journal, 105(6), 46-49.

Rodrigo, R. (2017, June 13). The flying disc is rising even higher. The Star Online. Retrieved from https://www.thestar.com.my/metro/scoreboard/2017/06/13/the-flying-disc-is-risingeven-higher-ultimate-frisbee-is-catching-on-among-students-in-schools-and/.

Sheppard, J. M. \& Young, W. B. (2006). Agility literature review: Classifications, training and testing. Journal of sports sciences, 24(9), 919-932.

Singh, P. \& Choudhary, R. (2016). Agility of netball players pertaining to different playing positions and levels. International Journal of Physical Education, Sports and Health.

Stowdashay (2011). Ultimate Frisbee - Positions. Retrieved from http://stowdashay.blogspot.my/2011/06/ultimate-frisbee-positions.html.

Talip, N. K. A. \& Kadir, Z. A. (2018). Acute Effects of Unilateral versus Bilateral Resistance Training on Heart Rate, Blood Pressure and Rate of Perceived Exertion. Jurnal Sains Sukan Dan Pendidikan Jasmani, 7(2), 61-75.

UK Ultimate (2016). What is Ultimate. Retrieved from www.ukultimate.com.

UKU-National Governing Body for Sport Ultimate in United Kingdom and North Ireland, (2008). What is Ultimate. www.ukultimate.com.

USA Ultimate. (2010). USA Ultimate Rules of Ultimate 11th Edition. Boulder, Colorado: USA Ultimate. Retrieved from http://www.usaultimate.org/assets/1/Page/11th edition (pdf for web).pdf

USA Ultimate. (2015). About Ultimate. Retrieve from https://www.usaultimate.org/about/.

Wood, R. (2008). Fitness Components for Ultimate Frisbee. Topend Sports. Retrieved from https://www.topendsports.com/sport/disc-sports/ultimate/fitness.

Yu, C. K. (2014). Locomotion patterns and heart rates of amateur Ultimate Frisbee players during match-play (Doctoral dissertation, Humboldt State University). 
